\title{
BENCHMARKING NA AVALIAÇÃO DE IMPACTO AMBIENTAL: O SISTEMA MINEIRO FRENTE ÀS MELHORES PRÁTICAS INTERNACIONAIS
}

\author{
Benchmarking performance: Environmental Impact Assessment in \\ Minas Gerais - Brazil
}

\author{
Maria Rita Raimundo e Almeida \\ Universidade Federal de Uberlândia, Uberlândia, Minas Gerais, Brasil \\ mrralmeida@iciag.ufu.br \\ Marcelo Montaño \\ Universidade de São Paulo, São Carlos, São Paulo, Brasil \\ minduim@sc.usp.br
}

Artigo recebido em 05/02/2014 e aceito para publicação em 06/01/2015

RESUMO: No Brasil, a Avaliação de Impactos Ambientais (AIA) e o licenciamento ambiental são considerados instrumentos da Política Nacional de Meio Ambiente. Apoiados pela Resolução CONAMAn 237/1997, cada estado brasileiro possui seu próprio sistema para aplicação destes instrumentos. Diante da diferenciação dos procedimentos adotados em cada estado e da existência de críticas à sua utilização, $\mathrm{o}$ presente trabalho tem por objetivo verificar como o sistema de AIA estabelecido em Minas Gerais vem se desenvolvendo frente às boas práticas internacionais. Para isto, foram consideradas as informações obtidas através de revisão de literatura, análise de processos e entrevistas com atores envolvidos. Entre os pontos positivos do sistema mineiro estão: a descentralização do processo de licenciamento, a proximidade entre os técnicos do órgão ambiental e o empreendedor e a decisão participativa ao ser tomada pelo Conselho Estadual de Meio Ambiente. Quanto às deficiências, elas concentram-se na generalização do escopo dos estudos, na não participação da população afetada, na falta de consideração de alternativas para o projeto, na ausência da avaliação de impactos cumulativos e na modalidade de licenciamento corretivo. Uma vez identificadas as deficiências, tornam-se necessárias ações que visem a melhoria de seu desempenho.

Palavras-chave: Avaliação de Impacto Ambiental. Licenciamento Ambiental. Minas Gerais. Benchmarking.

ABSTRACT: In Brazil, the Environmental Impact Assessment (EIA) and Environmental Licensing are considered instruments of the National Environmental Policy. Supported by CONAMA Resolution n ${ }^{\circ}$ 237/1997, each Brazilian state has its own system for implementing these instruments. Due to the differences among the procedures adopted in each state and the existence of critical of its use, this study aims to determine how the EIA system established in Minas Gerais has been developing in the face of international best practices. For this, the information was obtained through the literature review, process analysis and interviews with key actors. Among the positive points of the Minas Gerais system are: the decentralization of the licensing process, the proximity between the technical of environmental agency and entrepreneur and participative decision to be taken by the State Environmental Council. As for weaknesses, they concentrate on the generalization of the scope of the studies, no population participation, consideration of project alternatives, no assessment of cumulative impacts and the type of corrective licensing. Once identified system weaknesses become necessary actions aimed at improving its performance.

Key-words: Environmental Impact Assessment. Environmental Licensing. Minas Gerais. Benchmarking.

DOI: http://dx.doi.org/10.1590/1982-451320150106 


\section{INTRODUÇÃO}

A Avaliação de Impactos Ambientais (AIA) é um instrumento da Política Nacional do Meio Ambiente (BRASIL, 1981), cuja aplicação está associada ao licenciamento, fornecendo suporte para a análise das solicitações de licença ambiental nos casos de empreendimentos com potencial de causar significativo impacto ambiental.

A regulamentação dada pela Resolução CONAMA $\mathrm{n}^{\circ}$ 237/1997 indica a possibilidade de definição, pelo órgão ambiental competente, de procedimentos específicos para o processo de licenciamento e AIA (CONAMA, 1997, Artigo 12), o que implica, na prática, que os estados brasileiros apresentam seus próprios sistemas, estabelecidos de acordo com o contexto e as especificidades técnicas e institucionais encontradas em cada um. Todavia, os estados devem respeitar, na edição dos seus procedimentos, as normas gerais já estabelecidas pela União.

Diante da existência de críticas ao funcionamento da AIA (MORGAN, 2012; MPF, 2004) e das diferenças verificadas na organização dos sistemas estaduais e federal, em termos de sua estruturação e funcionamento, entende-se ser de interesse para a comunidade de praticantes (consultores, técnicos dos órgãos ambientais $\mathrm{e}$ acadêmicos) conhecer o nível de aproximação dos sistemas de AIA com um quadro referencial de boas práticas. Sendo assim, o presente trabalho tem por objetivo verificar como o sistema de Avaliação de Impactos Ambientais e licenciamento estabelecido em Minas Gerais vem se desenvolvendo frente ao conjunto de boas práticas internacionais associadas à aplicação destes instrumentos.

\section{ASPECTOS METODOLÓGICOS}

A análise descritiva empregada no presente artigo baseou-se na comparação entre o que rege as melhores práticas difundidas internacionalmente para a AIA e o funcionamento do sistema mineiro. A identificação das melhores práticas foi baseada em revisão da literatura e apoiada nos princípios internacionalmente disseminados para o instrumento, principalmente pela International Association for Impact Assessment - IAIA (Associação Internacional para a Avaliação de Impactos), que busca sintetizar as diferentes visões dos atores envolvidos no processo. Por sua vez, o diagnóstico do funcionamento do sistema mineiro de licenciamento e da AIA foi feito através de revisão de literatura, da análise de alguns processos de licenciamento e da realização de entrevistas com atores envolvidos.

\section{MELHORES PRÁTICAS EM AVALIAÇÃO DE IMPACTOS AMBIENTAIS}

A IAIA vem divulgando o que denomina de Princípios de Melhores Práticas em AIA com a finalidade de "promover uma prática efetiva da avaliação do impacto ambiental consistente com os sistemas institucionais e processuais em vigor nos diferentes países" (IAIA, 1999, p.2). Estes princípios dividem-se em Princípios Básicos e Princípios Operacionais. Os primeiros aplicam-se a todos os estágios da AIA e também à Avaliação Ambiental Estratégica (AAE) e regem que a AIA deve ser útil, rigorosa, prática, relevante, custo-eficaz, eficiente, adaptativa, participativa, interdisciplinar, confiável, integrada, transparente e sistemática. Os Princípios Operacionais referem-se à aplicação dos Princípios Básicos aos vários passos e às atividades específicas do processo de AIA, tais como seleção de ações, definição do âmbito, exame de alternativas, análise de impactos, mitigação e gestão de impactos, avaliação do significado, elaboração e revisão do EIA, decisão e acompanhamento.

Assim, o processo de AIA deve ser aplicado o quanto antes no processo de decisão e ao longo do ciclo de vida da atividade proposta; a todas as propostas de desenvolvimento que possam potencialmente causar efeitos significativos; deve considerar os impactos biofísicos e os fatores socioeconômicos relevantes, incluindo a saúde, a cultura, a igualdade de gênero, o estilo de vida, a idade e os efeitos cumulativos consistentes com o conceito e os princípios do desenvolvimento sustentável; deve promover o envolvimento e a participação ativa das comunidades e dos setores econômicos afetados por uma proposta, bem como do público interessado; e estar de acordo 
com atividades e medidas internacionalmente aceitas.

A AIA é iniciada com a apresentação da proposta de projeto, pelo empreendedor, à organização responsável pela tomada de decisão, que pode ser uma empresa privada, um organismo financeiro, uma agência de desenvolvimento ou um órgão governamental; sendo este último o caso mais geral (SÁNCHEZ, 2008) e onde se insere o processo de licenciamento ambiental. Conhecida a proposta, deve-se estimar seu potencial de causar impacto em função do potencial poluidor do empreendimento e da resiliência do meio em que ele será inserido.

A determinação do potencial de causar impacto é realizada na etapa conhecida como triagem, que inclui procedimentos para determinar se a proposta deverá ou não estar sujeita à AIA, e em caso afirmativo, a que nível de detalhe (IAIA, 1999). A triagem representa uma fase crítica de decisão (WOOD; BECKER, 2005) e reflete o primeiro nível de compromisso do sistema de AIA com a proteção ambiental (RAJARAM; DAS, 2011). Independente dos tipos de critério utilizados para a realização desta etapa (listas positivas, negativas, critérios de corte, localização do empreendimento, recursos ambientais potencialmente afetados e análise caso a caso), eles devem ser claros e aplicados de forma sistemática, de modo que ocorra uma padronização do processo. Além disso, os critérios devem ser de tal modo estabelecidos que permitam a separação das atividades ou empreendimentos que têm potencial de causar impacto significativo daqueles em que o potencial de causar impacto é insignificante.

Identificado o potencial de causar impactos significativos, passa-se à etapa seguinte (escopo) onde se definirá a profundidade e a abrangência do estudo a ser apresentado. O objetivo fundamental é concentrar no que importa para os tomadores de decisão para determinar a aprovação ou não de uma proposta (KENNEDY; ROSS, 1992). A fase de escopo se torna mais enriquecida e robusta quando envolve a participação dos interessados, aumentando as chances para que pontos relevantes para os diferentes envolvidos sejam incluídos na análise e discussão. Esta etapa culmina com a elaboração de um Termo de Referência (TR) por parte do órgão ambiental, contendo os tópicos a serem abordados no estudo ambiental. A padronização dos TRs, seja para diferentes tipos de empreendimentos ou para diferentes regiões, por um lado torna o processo mais rápido, mas por outro pode fazer com que questões específicas daquela combinação projeto/local sejam desconsideradas e que recursos e tempo sejam desperdiçados com outras questões sem importância.

Um Estudo de Impacto Ambiental (EIA) deve apresentar uma síntese clara e concisa da caracterização do empreendimento, da condição do meio onde será implantado o projeto (diagnóstico ambiental), descrever os prováveis impactos ambientais (prognóstico ambiental), caracterizar as propostas de medidas de mitigação e compensatórias, a importância dos impactos residuais e apresentar sugestões para outros estudos de acompanhamento (ROSS; MORRISON-SAUNDERS; MARSHALL, 2006). A elaboração do estudo deve ir além de apenas contemplar os tópicos presentes no TR: é necessário que haja relação entre o diagnóstico, os impactos da alternativa selecionada e a proposição das medidas ambientais e programas de monitoramento. Se a delimitação do âmbito de abrangência das informações do estudo não for orientada para os impactos principais, um esforço excessivo de trabalho e pesquisa podem ser despendidos para a avaliação de impactos não significantes, levando a uma longa e custosa etapa de elaboração (MIDDLE; MIDDLE, 2010), normalmente voltados para extensas seções de diagnóstico (ocupando quase a totalidade dos estudos) sem, contudo, abordar de forma objetiva os fatores relevantes. É o que Sánchez (2008, p.163) chama de abordagem exaustiva, ou seja, o estudo "busca um conhecimento quase enciclopédico do meio e supõe que quanto mais se disponha de informação, melhor será a avaliação".

A proposição de alternativas tecnológicas e locacionais, considerada por Paliwal (2006) como um dos princípios de melhores práticas da AIA, também deve ser considerada na elaboração dos estudos, a fim de que opções mais viáveis ambientalmente sejam escolhidas. Como o potencial de causar impacto é função da tipologia do empreendimento e do local em que se pretende implantar o projeto, sem um estudo de alternativas locacionais a avaliação de impactos fica reduzida apenas à proposição de medidas para 
remediar impactos que poderiam ser evitados se um local mais adequado houvesse sido escolhido.

A análise técnica tem como objetivo verificar e determinar se o estudo de impacto ambiental apresenta uma avaliação adequada da relevância dos impactos ambientais a serem causados pelo projeto e se existe qualidade suficiente para a tomada de decisões (EPA, 2003). Além de basearse na verificação do atendimento ao TR, a etapa de análise técnica poderia se beneficiar da utilização de ferramentas para revisão da qualidade dos estudos de impacto, contribuindo para a padronização nas avaliações realizadas pelos órgãos ambientais durante esta etapa (ALMEIDA et al., 2012).

O envolvimento do público na tomada de decisão é um componente fundamental do processo de AIA (HARTLEY; WOOD, 2005), sendo apontado como o fator mais influente sobre a configuração dos projetos (KOLHOFF; RUNHAAR; DRIESSEN, 2009) e que pode ajudar a garantir a abrangência, qualidade e eficácia da AIA, levando a melhores decisões (GLASSON; THERIVEL; CHADWICK, 2005). A efetiva participação do público deve envolver consultas via comunicação bidirecional entre o desenvolvedor do estudo ambiental ou empreendedor e o público e entre o órgão ambiental ou de Governo e as comunidades locais (PETTS, 1999). Ela serve como ferramenta de negociação e entendimentos entre empreendedor, órgão ambiental e comunidade afetada.

De acordo com os princípios internacionais de boas práticas, a participação do público deve ocorrer o mais cedo possível, começando na préavaliação e continuar por todo o processo de AIA (VASCONCELOS; HAMILTON; BARRETT, 2010), já que seus vários estágios fornecem oportunidades para o envolvimento dos diferentes atores (DEVLIN; YAP, 2008). Em países avançados com relação à AIA, a participação não só ocorre na tomada de decisão, mas em estágios anteriores como a triagem e o escopo (MORRISON-SAUNDERS; EARLY, 2008). A participação na fase de escopo é crucial para sua qualidade e da AIA como um todo (HOKKANEN; JANTUNEN, 2012). Soneryd (2004) ressalta que o envolvimento público é recomendado não só no escopo e revisão dos estudos, mas também no monitoramento e auditoria, o que confere ao público a oportunidade de participar da verificação dos resultados nos estágios finais do processo. Vale lembrar que só consegue participar quem tem informação; assim, de alguma forma a população ou qualquer outro envolvido deve receber meios de informar-se sobre como o processo ocorre e sobre o que está acontecendo, sendo uma destas formas a disponibilização dos estudos realizados, principalmente, do Relatório de Impacto Ambiental (RIMA).

Uma das formas de participação presentes na legislação brasileira é a audiência pública na fase de análise dos estudos. A audiência pública é uma reunião que tem por finalidade expor aos interessados as informações e os resultados obtidos pelo EIA/ RIMA sobre uma obra ou atividade potencialmente causadora de significativo impacto ambiental, dirimindo dúvidas e recolhendo dos presentes críticas e sugestões a respeito para subsidiar a decisão quanto ao seu licenciamento ambiental (CONAMA, 1987). Ela é considerada um mecanismo de participação social, porém a sociedade não tem poder decisório, somente consultivo, ainda que possa determinar a necessidade de maiores aprofundamentos de questões assinaladas nas discussões pelos participantes (TAMBELLINI, 2012).

Com a finalidade de melhorar a participação pública na AIA e estimular o debate entre as partes interessadas e obter como resultado melhores projetos, governança participativa e, em última instância, um mundo mais sustentável, a IAIA criou um guia com os Princípios Internacionais da Melhor Prática da Participação Pública (ANDRÉ et al., 2006). Nos Princípios Básicos, a participação pública deve ser adaptada ao contexto, informativa e pró-ativa, adaptável e comunicativa, inclusiva e equitativa, educativa, cooperativa e imputável; e nos Princípios Operacionais, deve ser iniciada cedo no processo e sustentada ao longo dele, bem planejada e focalizada em questões negociáveis, estimulante aos participantes, diferenciada e otimizada, aberta e transparente, orientada para o contexto, credível e rigorosa. Como Orientações de Desenvolvimento, a fim de melhorar os resultados da participação pública, todos os atores devem promover ativamente o acesso 
à informação útil e relevante, o envolvimento e participação de alto nível na decisão, as formas criativas de envolver as pessoas, a justiça e a equidade de participação.

A decisão resultante do processo de AIA diz respeito à viabilidade ambiental do projeto da maneira como ele foi proposto em termos de sua concepção tecnológica e localização. Atestar a viabilidade ambiental dos projetos previamente à sua implantação constitui a finalidade precípua da AIA associada ao licenciamento como instrumentos de política e gestão do meio ambiente (MONTAÑO; SOUZA, 2008). Esta decisão deveria ser balizada pela opção de projeto mais viável do ponto de vista ambiental e ser apoiada nos resultados da análise técnica e também levar em consideração todas as questões abordadas durante a consulta pública. Ainda, é necessário que os fatores ambientais sejam considerados e não sejam sufocados pelos interesses econômicos ou de outra natureza.

Comprovada a viabilidade do projeto, ele pode ser aprovado e obter as licenças necessárias para sua implantação e operação. Uma vez implantado, acontecem as etapas pós-aprovação, sendo que a eficiência do processo de AIA está condicionada à aplicação completa das etapas pré e pós-decisão para um projeto (MOREIRA, 1989).

O objetivo geral do monitoramento é determinar se os impactos reais de um projeto proposto correspondem aos impactos previstos no EIA (BADR, 2009) e se as medidas propostas são suficientes para a mitigação dos impactos. Além disso, visa assegurar a implementação da atividade de forma satisfatória e promover ajustes e correções necessárias nos procedimentos. Por sua vez, o acompanhamento é realizado pelo órgão ambiental a fim de verificar os compromissos assumidos pelo empreendedor, quando da implantação do empreendimento, e para validar a licença ambiental emitida, caso o empreendimento persista na condição de adequado e viável ambientalmente. O monitoramento/acompanhamento tem a função de verificar se a previsão dos impactos e se as medidas ambientais propostas estão sendo suficientes para que os impactos causados estejam dentro de limites aceitáveis (ou padrões de qualidade) e, portanto, se o empreendimento continua a ser ambientalmente viável. Por isso, ele é o elemento que pode transformar um estudo ambiental de um processo estático em um processo dinâmico, sendo a lacuna entre os estudos ambientais e a efetiva implementação e administração de um projeto (NOBLE; STOREY, 2005).

\section{ESTRUTURAÇÃO DO SISTEMA MINEIRO DE AIA E LICENCIAMENTO AMBIENTAL}

O Sistema Estadual do Meio Ambiente e Recursos Hídricos de Minas Gerais (SISEMA) é formado pela Secretaria de Estado do Meio Ambiente e Desenvolvimento Sustentável (SEMAD), pelos Conselhos Estaduais de Política Ambiental (COPAM) e de Recursos Hídricos (CERH) e pelos órgãos vinculados: Fundação Estadual do Meio Ambiente (FEAM), Instituto Estadual de Florestas (IEF) e Instituto Mineiro de Gestão das Águas (IGAM).

A SEMAD tem por finalidade planejar, organizar, dirigir, coordenar, executar, controlar, fiscalizar e avaliar as ações relativas à proteção e à defesa do meio ambiente, ao gerenciamento dos recursos hídricos e à articulação das políticas de gestão dos recursos ambientais, visando ao desenvolvimento sustentável (MINAS GERAIS, 2011). O COPAM é um conselho normativo, consultivo, colegiado e deliberativo que formula a política estadual do meio ambiente, através de suas Deliberações Normativas, tendo inclusive, poder de polícia, o que o legitima a aplicar sanções previstas em lei, como multas ou embargos e suspensão das atividades (MINAS GERAIS, 1977). A FEAM executa e implanta políticas de preservação e proteção do meio ambiente, monitora a qualidade do ar, água e solo, promove a educação e a pesquisa ambiental, fiscaliza projetos e empresas, além de subsidiar o COPAM no licenciamento ambiental e apoiar tecnicamente as instituições do SISEMA (MINAS GERAIS, 2008b); o IEF propõe, coordena e executa a atividade agrícola, pecuária e florestal (MINAS GERAIS, 1962), sendo que após a Lei Delegada $n^{\circ}$ 180 de 2010 teve sua atuação focada nas atividades ligadas ao desenvolvimento e à conservação florestal, no estímulo às pesquisas científicas relacionadas à conservação da biodiversidade e à gestão de áreas 
protegidas; e o IGAM é responsável por planejar e promover ações direcionadas à preservação da quantidade e da qualidade das águas (MINAS GERAIS, 2008a).

Existem, ainda, as Superintendências Regionais de Regularização Ambiental (SUPRAMs) que têm por finalidade planejar, supervisionar, orientar e executar as atividades relativas à política estadual de proteção do meio ambiente e de gerenciamento dos recursos hídricos, formulada e desenvolvida pela SEMAD dentro de suas áreas de abrangência territorial, sendo nove no total: Central-Metropolitana, Alto São Francisco, Jequitinhonha, Leste de Minas, Noroeste, Norte de Minas, Sul de Minas, Triângulo Mineiro e Alto Paranaíba e Zona da Mata.

Até 2003 , todo o processo de regularização era realizado de modo centralizado em Belo Horizonte, e de forma segmentada: ao IEF cabia a avaliação dos impactos sobre a vegetação e regularização de reservas legais e intervenção em áreas de preservação permanente; ao IGAM, a análise e concessão do uso dos recursos hídricos; e à FEAM, a avaliação dos impactos concernentes aos resíduos sólidos, ruídos, efluentes líquidos e atmosféricos, provenientes de atividades industriais, minerárias e obras de infraestrutura (RODRIGUES, 2010). Contudo, iniciou-se um processo de mudanças na organização interna e nas funções dos órgãos e instituições integrantes do SISEMA. Foi, então, adotado um modelo interdisciplinar, compartilhado pela FEAM, IEF e IGAM e onde um parecer único é fornecido para cada processo de licenciamento ambiental. Além da aproximação das referidas entidades, foi estabelecida a regionalização na qual, sob o aspecto técnico-operacional, todos os processos de regularização ambiental passam a ser formalizados nas respectivas SUPRAMs.

\section{O PROCESSO DE AVALIAÇÃO DE IMPACTO AMBIENTAL E LICENCIAMENTO EM MINAS GERAIS}

As principais legislações do processo de Licenciamento no estado de Minas Gerais são a Deliberação Normativa (DN) do COPAM n ${ }^{\circ}$ 74/2004, que trata de custos e classifica os empreendimentos em 6 classes de acordo com o porte e o potencial poluidor; a Resolução SEMAD n 390/2005, que estabelece normas para a integração dos processos de autorização ambiental de funcionamento (AAF), licenciamento ambiental, de outorga de direito de uso de recursos hídricos e de autorização para exploração florestal; e o Decreto ${ }^{\circ} 44.844 / 2008$, que entre outras funções, estabelece normas para o licenciamento ambiental e AAF.

$\mathrm{O}$ processo de licenciamento ambiental em Minas Gerais é iniciado com o recebimento da solicitação de licenciamento do empreendedor/ consultoria, mediante o preenchimento do Formulário de Caracterização do Empreendimento (FCE) com informações, principalmente, acerca do porte e localização do projeto em questão.

A etapa de triagem obedece, inicialmente, a Resolução CONAMA n 237/1997, onde é verificada a necessidade ou não do licenciamento ambiental. Nos casos negativos, é emitida uma Certidão de Dispensa. Nos casos afirmativos, com base nas informações do FCE e na DN 74/2004, o empreendimento é classificado em uma das 6 classes a seguir, de acordo com seu porte e potencial poluidor/degradador: Classe 1: pequeno porte e pequeno ou médio potencial poluidor; Classe 2: médio porte e pequeno potencial poluidor; Classe 3: pequeno porte e grande potencial poluidor ou médio porte e médio potencial poluidor; Classe 4: grande porte e pequeno potencial poluidor; Classe 5: grande porte e médio potencial poluidor ou médio porte e grande potencial poluidor; e Classe 6 : grande porte e grande potencial poluidor.

Para classificar o empreendimento nas classes, são consideradas as listagens de tipologias de empreendimentos constantes nos anexos da DN $n^{\circ} 74 / 2004$. Para cada uma das tipologias, esta norma classifica a atividade em um potencial poluidor (pequeno, médio ou grande), que é intrínseco a ela e está de acordo com suas interferências no solo, ar e água; e em um porte (pequeno, médio ou grande) que depende de algum quesito deste empreendimento, que pode ser produção bruta, área útil, volume de matéria-prima processada, extensão, número de empregados, entre outros. De posse das informações do enquadramento do empreendimento em seu potencial poluidor e porte, é utilizada a Tabela A-1 da $\mathrm{DN} \mathrm{n}^{\circ} 74 / 2004$ (Quadro 1) e tem-se a classe do empreendimento. 
Quadro 1 - Critérios de classificação do empreendimento, segundo o potencial poluidor/degradador e o porte do empreendimento.

\begin{tabular}{|c|c|c|c|c|}
\hline & & \multicolumn{3}{|c|}{ Potencial poluidor/degradador geral da atividade } \\
\hline & & $\mathrm{P}$ & $\mathrm{M}$ & G \\
\hline \multirow{3}{*}{ Porte do empreendimento } & $\mathrm{P}$ & 1 & 1 & 3 \\
\hline & M & 2 & 3 & 5 \\
\hline & $\mathrm{G}$ & 4 & 5 & 6 \\
\hline
\end{tabular}

Fonte: Copam (2004).

Esta classificação dos empreendimentos orienta a triagem quanto aos estudos e documentos que irão nortear o processo de licenciamento ambiental. Empreendimentos de menor porte e de menor potencial poluidor (classes 1 e 2) têm sua solicitação de licença instruída com base na AAF, um instrumento de natureza declaratória, sujeito apenas ao cadastro da atividade/empreendimento, à apresentação de documentos de natureza formal e à assinatura de termo de responsabilidade (VIANA; BURSZTYN, 2010). Entre estes documentos apresentados estão aqueles que comprovam a formalização da empresa e a Anotação de Responsabilidade Técnica (ART) do profissional habilitado responsável pelo controle ambiental do empreendimento durante o período de vigência da AAF. Com relação ao termo de responsabilidade, o responsável legal pelo empreendimento se compromete a instalar ou operar seu empreendimento dentro das normas e padrões ambientais vigentes. No caso de tais empreendimentos, o processo não prevê o envolvimento do COPAM e não há qualquer tipo de vistoria ou inspeção prévia.

Para os empreendimentos classes de 3 a 6, o processo de licenciamento é apoiado na AIA, existindo a necessidade da elaboração de estudos ambientais, que podem ser o Estudo de Impacto Ambiental e respectivo Relatório de Impacto Ambiental (EIA/RIMA) ou o Relatório de Controle Ambiental (RCA). A necessidade de elaboração de EIA/RIMA é definida de acordo com o Art. $2^{\circ}$ da Resolução CONAMA n 001/1986 e também de acordo com a discricionariedade do órgão ambiental (triagem caso a caso), que, em função da localização e das características do empreendimento, pode julgar necessária a elaboração do EIA/RIMA. O RCA é apresentado em caso de dispensa de EIA/RIMA para empreendimentos e/ou atividades em que o porte e/ ou o potencial poluidor/degradador geram impactos ambientais de menor importância. Não existe regulamentação legal para o RCA, estabelecendo seu conteúdo e aplicação quando da dispensa de EIA/ RIMA, mas em termos práticos isto já é consolidado.

Oprocesso de triagem culmina coma emissão, pelo Sistema Integrado de Informação Ambiental (SIAM), do Formulário de Orientação Básica (FOB), que apresenta qual a classe em que o empreendimento foi enquadrado e lista a documentação e o tipo de estudo de impacto (EIA/RIMA ou RCA) necessários à formalização do processo.

Tanto nos casos de EIA/RIMA como de RCA, o escopo é definido por Termos de Referência pré existentes. Em sítio eletrônico da SEMAD é disponibilizado o TR geral para a elaboração do EIA/ RIMA e alguns TRs específicos para determinadas atividades, como atividades agrossilvopastoris, minerárias, indústria química, indústria alimentícia, infraestrutura de energia, infraestrutura de saneamento, parcelamento do solo, serviços de segurança e sistema de tratamento térmico de resíduos sólidos urbanos com geração de energia elétrica.

Após a elaboração e protocolo dos estudos solicitados, acompanhados da documentação necessária, o processo entra em fase de análise. Inicialmente, o estudo de impacto é submetido a uma verificação do cumprimento do Termo de Referência, em relação ao conteúdo estabelecido previamente. 
Em seguida, tal conteúdo é analisado em relação aos aspectos metodológicos empregados nos levantamentos realizados e na avaliação dos impactos ambientais, procurando-se verificar, sobretudo, se as informações apresentadas são suficientes para orientar a tomada de decisão. Durante esta etapa são realizadas vistorias ao local pretendido para a instalação dos empreendimentos, de modo a auxiliar a equipe técnica (formada por profissionais de diversas áreas) responsável pela análise das solicitações de licença ambiental. Nos casos de maior complexidade são realizadas reuniões multidisciplinares para a avaliação do estudo e em poucos casos são envolvidas outras entidades ambientais na análise técnica, como órgãos gestores de Unidades de Conservação, Comitê de Bacias, entre outros.

A análise dos estudos pode apontar que as informações prestadas são insuficientes para a tomada de decisão e, então, informações complementares são solicitadas. Finalizada a análise, um parecer técnico único é emitido, sendo revisto e aprovado pelo diretor da área técnica e pela Diretoria de Controle Processual. Nesta etapa, o pareceré encaminhado para julgamento pelas Unidades Regionais Colegiadas (URC) do COPAM. As URCs são unidades deliberativas e normativas, encarregadas de analisar e compatibilizar, no âmbito de sua atuação territorial, planos, projetos e atividades de proteção ambiental com a legislação aplicável e propor as políticas de conservação e preservação do meio ambiente e para o desenvolvimento sustentável, competindo-lhe, entre outros, decidir sobre pedidos de concessão de licença ambiental, inclusive as concedidas em caráter corretivo (MINAS GERAIS, 2007).

A oportunidade de participação pública acaba por acontecer somente antes da emissão da licença, através da realização de audiências públicas: as audiências de atividades sujeitas a EIA/RIMA serão realizadas durante o processo de análise e tramitação do EIA, antes da apresentação ao COPAM do Parecer Técnico por ela elaborado (COPAM, 1994). Os procedimentos para realização de uma audiência pública são expressos na DN n 12/1994.

Apesar da previsão normativa, a audiência pública não é comum nos processos de licenciamento da SUPRAM. Embora ocorra toda a publicidade com a divulgação em jornais do período para a solicitação de audiência, os agentes que poderiam solicitar a sua realização (próprio órgão ambiental, COPAM, Poder Público Estadual ou Municipal, Ministério Público, entidade civil ou grupo de 50 ou mais cidadãos) raramente o fazem.

As decisões sobre a viabilidade ambiental do empreendimento são tomadas pelas URCs do COPAM. Os processos são colocados em votação diante da plenária e, em geral, as decisões são tomadas por consenso, excetuando-se os processos polêmicos. A presença do empreendedor na reunião da URC do COPAM que vai decidir sobre a viabilidade do projeto de seu interesse não é obrigatória. Contudo, quando ocorre algum destaque no processo por parte dos conselheiros, o empreendedor ou a consultoria quando presentes podem prestar os esclarecimentos necessários, evitando que o processo saia de pauta e seja encaminhado para a próxima reunião. Os esclarecimentos aos destaques dos processos também podem ser realizados pelos técnicos da SUPRAM.

Por fim, dado o parecer final e, no caso de aprovação do empreendimento, a licença prévia (LP) é emitida. Com o cumprimento das condicionantes e exigências contidas na LP e também a apresentação do Plano de Controle Ambiental (PCA), onde são descritas todas as medidas ambientais e programas de monitoramento, é emitida a licença de instalação (LI); cumprida as demais condicionantes e exigências, a licença de operação (LO) é expedida e o empreendimento entra em funcionamento. As decisões finais a respeito da emissão da LI e LO também são tomadas pelo COPAM.

Nas etapas pós-aprovação da $\mathrm{LO}$ e da licença de operação corretiva (LOC), são acompanhados pela SUPRAM os programas de monitoramento através dos Relatórios de Avaliação do Desempenho Ambiental (RADA), que garantem a legalidade ambiental do empreendimento e a renovação da licença ambiental. A sociedade pode participar do processo de acompanhamento, denunciando as ações do empreendimento implantado.

Vale destacar que em MG é comum a existência do licenciamento em caráter corretivo, ou seja, o empreendimento foi implantado anteriormente à legislação ambiental ou está em operação de forma 
irregular e, então, busca sua regularização ambiental. Neste caso, estão envolvidos dois tipos de licença: Licença de Instalação Corretiva (LIC) ou a Licença de Operação Corretiva (LOC). O licenciamento corretivo não envolve penalidades somente nos casos da implantação do empreendimento ser anterior a legislação ou por denúncia espontânea, mas conta, na maioria das vezes, com a celebração de um Termo de Ajustamento de Conduta (TAC) junto ao órgão ambiental.

A modalidade do licenciamento corretivo foi criada visando a regularização ambiental de empreendimentos que tiveram sua instalação anterior à implementação das normas ambientais de regularização ambiental. No entanto, ela tem sido utilizada como artimanha do empreendedor: o empreendimento é instalado sem passar pelo processo de licenciamento e o empreendedor, então, solicita o licenciamento corretivo. Uma vez instalado o projeto, os impactos da fase de planejamento e instalação já estão consolidados e, a própria desativação do projeto pode acarretar mais impactos, sendo que, neste contexto, a licença acaba por ser emitida, pois é mais viável ambientalmente manter seu funcionamento do que encerrá-lo.

\section{BENCHMARKING: SISTEMA MINEIRO DE AVALIAÇÃO DE IMPACTOS AMBIENTAIS FRENTE ÀS MELHORES PRÁTICAS}

O sistema mineiro foi analisado através da comparação entre o seu funcionamento e as melhores práticas para a utilização da AIA. O resumo da análise é apresentado na Quadro 2.

Oreferido sistema éapoiado emum arcabouço legal, onde as legislações estaduais complementam as federais e estabelecem os procedimentos e critérios a serem adotados, adaptando estes instrumentos ao contexto do estado. De modo geral, as bases legais são orientadas pelos princípios e boas práticas da AIA. Os critérios utilizados são claros, sobretudo, na etapa de triagem dos processos. A possibilidade de exigência de estudos menos aprofundados, como o RCA, demonstram a flexibilidade e a simplificação do processo de AIA para os casos menos complexos, resultando em economia de tempo e recursos.
A estruturação do órgão ambiental, descentralizada e regionalizada nas SUPRAMs, gera maior proximidade do órgão ambiental com o empreendedor, acarretando em maior procura por regularização: de acordo com dados do SIAM, esta estruturação aumentou em quase $600 \%$ a procura por regularização ambiental dos empreendimentos que constituem a Agenda Marrom (VIANA, 2007). Ainda, conforme a pesquisa de Viana e Bursztyn (2010), os atores envolvidos com o processo de licenciamento em MG apontam que a decisão de regionalizar o sistema ambiental foi um acerto: a regionalização estimula a regularização, um melhor controle ambiental e social, a participação da sociedade, a interiorização das diretrizes ambientais e a capacitação dos municípios, criando massa crítica no interior do Estado, embora aumente a influência de grupos de interesse (em especial, as prefeituras municipais) nas decisões dos conselhos. Por outro lado, com a regionalização o corpo técnico para análise dos processos fica reduzido, não possuindo especialistas nas diferentes áreas exigidas pela amplitude e multidisciplinaridade envolvida nos estudos. 
Benchmarking na avaliação de impacto ambiental: O sistema mineiro frente às melhores práticas internacionais Maria Rita Raimundo e Almeida, Marcelo Montaño

Quadro 2: Resumo da comparação entre o sistema mineiro e as melhores práticas

\begin{tabular}{|c|c|c|c|}
\hline Etapa & Melhores práticas & Sistema mineiro & Avaliação \\
\hline Triagem & $\begin{array}{l}\text { Padronização do processo: } \\
\text { critérios claros e aplicados de } \\
\text { forma sistemática. }\end{array}$ & $\begin{array}{l}\text { Baseada nas Resoluções } \\
\text { CONAMA 001/1986 e } 237 / 1997 \text { e } \\
\text { na DN Copam 74/2004 (6 classes). }\end{array}$ & $\begin{array}{l}\text { Os critérios são claros, mas deveriam envolver informações de localização } \\
\text { do empreendimento. Existem pressões sobre a divisão em classes da DN } \\
74 / 2004 \text { para que o empreendimento seja licenciado sem a AIA. }\end{array}$ \\
\hline Escopo & $\begin{array}{l}\text { Focado nas questões relevantes } \\
\text { para o projeto em questão (TR } \\
\text { específico para cada caso). }\end{array}$ & $\begin{array}{l}\text { TRs pré-existentes (específicos } \\
\text { para algumas tipologias) e } \\
\text { disponibilizados na página do } \\
\text { órgão ambiental. }\end{array}$ & $\begin{array}{l}\text { Os TRs generalizados e pré-definidos impossibilitam a análise das } \\
\text { especificidades do projeto e a possibilidade de participação. }\end{array}$ \\
\hline $\begin{array}{l}\text { Elaboração do } \\
\text { Estudo de Impacto } \\
\text { Ambiental }\end{array}$ & $\begin{array}{l}\text { O estudo deve abordar de forma } \\
\text { objetiva os fatores relevantes } \\
\text { e não deixar de apresentar um } \\
\text { estudo de alternativas. }\end{array}$ & $\begin{array}{l}\text { Estudos mal elaborados e que } \\
\text { raramente apresentam uma } \\
\text { avaliação das possíveis alternativas } \\
\text { tecnológicas e locacionais do } \\
\text { projeto. }\end{array}$ & $\begin{array}{l}\text { O sistema favorece a agilidade do processo, mas peca na exigência de } \\
\text { qualidade das informações apresentadas. }\end{array}$ \\
\hline
\end{tabular}

Padronização nas avaliações: poderia envolver a aplicação de

Análise técnica ferramentas de revisão (roteiros de análise) e o envolvimento de outros órgãos.
Baseada no cumprimento do TR e acompanhada por vistoria.
Modelo interdisciplinar tornou o processo mais ágil, mas poucas entidades (com maior capacidade técnica na sua área de atuação) são envolvidas no processo.

Deve: servir como ferramenta de negociação entre empreendedor, órgão ambiental e comunidade afetada; ser iniciada cedo

Participação no processo e sustentada ao longo dele; haver capacitação da população para participar (função do RIMA); ser aberta e transparente.

Deve optar pelo projeto mais viável ambientalmente, ser apoiada nos resultados da análise técnica e considerar as Decisão questões abordadas na consulta pública. Ainda, é necessário que os fatores ambientais não sejam sobrepostos pelos interesses de outra natureza.
Quando acontece, restringe-se a audiência pública associada à análise técnica do estudo.
Deveriam existir outras janelas de participação nas demais etapas da AIA, como na triagem e no escopo, e mecanismos mais eficazes para o envolvimento da população.
Tomada pelo COPAM embasada principalmente pelo parecer técnico.
A decisão ao ser tomada pelo COPAM não deixa de ser participativa. A análise técnica tem influência na decisão, mas ainda existem influências políticas e econômicas. Acompanhamento
Deve a companhar

o funcionamento do empreendimento, promovendo os ajustes necessários.
Vistorias e entrega de relatórios periódicos e por ocasião da renovação da licença (RADA)
Não ocorre na frequência desejada e são adotados os mesmos procedimentos para todos os empreendimentos, sejam eles capazes ou não de causar impacto significativo.

Organização dos autores. 
A fase de triagem é regulamentada principalmente pelas classes definidas na DN $74 / 2004$, cujos critérios de porte e potencial poluidor/ degradador têm sofrido constantes mudanças (como exemplo, cita-se o Edital de Chamamento Público aberto em 2012, disponível em http://www.semad. mg.gov.br/noticias/1/1532-edital-de-chamamentopublico-semadcopam-no-012012). Embora vise o aprimoramento do sistema, a crítica sobre estas mudanças recai sobre as pressões sofridas para que o enquadramento dos empreendimentos seja feito em classes inferiores (classes 1 e 2), ou seja, as alterações ampliam os limites para que o empreendimento seja considerado de pequeno porte e com isso passe a ser licenciado sem a AIA. Deste modo, empreendimentos que são capazes de causar alteração ao meio, mesmo que em pequena escala, são licenciados apenas com uma AAF.

Outra proposta de alteração a ser feita na DN 74/2004 visa sanar sua deficiência em relação à ausência de critérios locacionais na definição da classe do empreendimento. Encontra-se em discussão a implementação de um sistema de análise do fator locacional associado ao grau de vulnerabilidade ambiental da área onde se localizará o empreendimento, podendo este variar de 0 a 2 , de acordo com a vulnerabilidade do meio. Assim, além dos critérios de porte e potencial poluidor, o enquadramento dos empreendimentos em classes, que passariam a ser 8 ao invés de 6 , levaria em consideração a vulnerabilidade do meio, dada pelo Zoneamento Ecológico Econômico do Estado, aprovado pela $\mathrm{DN} \mathrm{n}^{\circ} 129 / 2008$. Esta modificação da legislação teve a minuta proposta em 2011 (SEMAD, 2011), mas até o momento ainda não foi aprovada. Vale destacar que timidamente algumas DNs para empreendimentos específicos, como a DN $n^{\circ} 138 / 2009$ para atividades agrossilvopastoris, já apresentavam critérios de localização para nortear a classe do empreendimento.

Ainda com relação à triagem, o modo como ela acontece em MG não abre espaço para o envolvimento e participação de outros atores além do órgão ambiental e, ainda, os processos de licenciamento corretivo são tratados da mesma forma que os de licenciamento preventivo.

O escopo é estipulado por TRs generalizados e pré-definidos, o que impossibilita a análise das especificidades do empreendimento em processo de licenciamento, podendo ocasionar a abordagem de temas irrelevantes e a omissão de aspectos fundamentais na análise de sua viabilidade ambiental. Além disso, os TRs pré-definidos não possibilitam nenhuma forma de participação e nem o envolvimento dos diferentes atores.

Os estudos envolvidos no processo (EIA/ RIMA e RCA) ainda são falhos na análise de alternativas e na avaliação de impactos cumulativos e sinérgicos. O RIMA, pela linguagem em que é apresentado e por falhas na sua disponibilização, não capacita a população para participar da decisão. Alguns estudos apresentados não cumprem de forma satisfatória todas as etapas de desenvolvimento necessárias, mas mesmo assim poucas complementações são solicitadas e poucos EIAs/RIMAs são reprovados por sua má qualidade. Se o órgão ambiental aceita estudos de baixa qualidade que pecam ao fornecer informações para a tomada de decisão, não é da parte do empreendedor/ consultor que melhores estudos serão desenvolvidos, uma vez que exigem mais tempo e recursos. Diante deste contexto, apesar dos processos se tornarem mais ágeis e com menor dispêndio de recursos, os objetivos do instrumento AIA não são alcançados. Em outras palavras, prioriza-se o tempo e a agilidade para análise dos processos e esquece-se da qualidade das informações que subsidiam a tomada de decisão.

Existe uma grande proximidade entre empreendedor/consultoria e técnicos do órgão ambiental, ocorrendo várias reuniões de discussão e esclarecimentos, o que facilita o andamento do processo, tornando-o mais veloz.

A adoção do modelo interdisciplinar, além de possibilitar uma avaliação integrada dos processos, torna a fase de análise técnica mais ágil ao diminuir o tempo de análise e emissão do parecer. Contudo, em raros casos são envolvidas outras entidades ambientais, o que empobrece a etapa que poderia ser mais substancial e criteriosa com a participação destas entidades, que possuem maior capacidade técnica na sua área de atuação.

A participação dentro do processo de licenciamento com AIA em Minas Gerais, apesar de 
cumprir os requesitos legais, não ocorre nas etapas anteriores à análise técnica e, nesta fase, acontece em poucos casos, sob a forma de audiência pública. Se a audiência não é solicitada pelo MP, entidade civil, Conselho de Meio Ambiente e 50 ou mais cidadãos, o órgão ambiental, na maior parte dos casos, não a faz. Quando a audiência é realizada, poucas contribuições são acrescentadas ao processo. Porém, cabe novamente ressaltar que quando há interesse em participar e envolvimento dos interessados, as janelas de participação disponibilizadas são suficientes para provocar intervenções nos processos.

Durante a reunião do COPAM para a decisão final sobrea viabilidade ambiental do projeto eemissão da licença ambiental, a presença do empreendedor/ consultoria e dos técnicos da SUPRAM agiliza o processo, uma vez que eles podem esclarecer dúvidas dos conselheiros, não sendo a decisão adiada para as próximas reuniões. A tomada de decisão final sobre a (in)viabilidade ambiental, e consequente (in) deferimento da licença, ao ser dado pelo COPAM, não deixa de ser uma forma participativa de decisão, pois este conselho envolve em sua composição diversos segmentos da sociedade. Cabe ressaltar a influência que a análise técnica tem na decisão, sendo um canal formal de comunicação e de competência.

No entanto, não se pode ignorar a importância que os meios não formais (interesses de outras naturezas que não a ambiental) têm na decisão: experiências internacionais indicam que os fatores políticos têm sido as forças motrizes por trás da introdução e prática da AIA (ELLIOTT; THOMAS, 2009), sendo que a dependência e a interferência política configuram um problema determinante na eficácia deste instrumento de gestão ambiental (FATORELLI; MERTENS, 2010; THEOPHILOU; BOND; CASHMORE, 2010). Embora estes meios não formais não sejam claramente documentados, a sua existência foi obsevada em alguns processos analisados e em conversas informais com atores envolvidos com o processo. As questões não formais apresentam interferência inclusive no tempo de tramitação dos processos: para projetos que envolvem outros interesses do governo, o tempo para emissão das licenças tende a ser mais curto, embora todas as obrigações legais sejam cumpridas. Assim, é necessário reconhecer a existência destes canais e monitorá-los para que as decisões tomadas não deixem de lado a função dos instrumentos licenciamento e AIA e baseiem-se em questões estritamente políticas e econômicas.

O monitoramento/acompanhamento do empreendimento por parte do órgão ambiental, conforme apontado pelos técnicos, muitas vezes, não ocorre na frequência desejada, gerando passivos ambientais que só tentarão ser resolvidos por ocasião da renovação ou do pedido de outra licença. Assim, a etapa de acompanhamento/monitoramento não é realizada de forma adequada, lembrando que sem ela, a AIA pode ser reduzida a um procedimento meramente formal, em vez de ser um exercício efetivo no gerenciamento ambiental (SADLER, 1996). Além disso, são adotados os mesmos procedimentos na etapa de monitoramento de todos os empreendimentos, sejam eles capazes ou não de causar impacto significativo.

\section{CONSIDERAÇÕES FINAIS}

A comparação do funcionamento do sistema de licenciamento com AIA em Minas Gerais com as melhores práticas permitiu a identificação de pontos positivos (contribuem para a efetividade do instrumento) e negativos (dificultam a efetividade do instrumento). Entre estes, pode-se destacar como boas características do sistema a descentralização do processo de licenciamento, a proximidade entre os técnicos do órgão ambiental e o empreendedor e a decisão participativa ao ser tomada pelo Conselho Estadual de Meio Ambiente, o COPAM.

Algumas das deficiências apresentadas estão em consonância com as deficiências encontradas nos sistemas de Avaliação de Impacto Ambiental ao redor do mundo (conforme apresentado por MORGAN, 2012), estando presentes na participação, na consideração de alternativas para o projeto e na avaliação de impactos cumulativos.

Contudo, no caso do sistema mineiro de AIA, a generalização do escopo dos estudos ambientais (TRs pré-definidos), as limitações verificadas em relação ao monitoramento (não ocorre na frequência adequada) e, principalmente, a utilização de mecanismos de 
"licenciamento corretivo" contribuem para afastálo do quadro de boas práticas descrito no trabalho, colocando em xeque a função e o caráter preventivo do instrumento.

Sendo assim, tornam-se necessárias ações que promovam o resgate do instrumento em relação aos princípios e fundamentos preconizados internacionalmente, a fim de assegurar condições para a melhoria de seu desempenho em sentido amplo. Neste sentido, identificar as experiências positivas e adaptá-las ao contexto presente no estado apresenta-se como uma estratégia importante e que deve ser levada em conta pelos órgãos gestores.

No caso do sistema mineiro de AIA, concluise pela necessidade de considerar não apenas o tempo de tramitação dos processos de licenciamento como indicador da efetividade do sistema, mas também a qualidade dos estudos e das decisões envolvidas. Além disso, deve-se reconhecer a importância do estudo de alternativas locacionais para a promoção da configuração mais favorável entre o projeto do empreendimento e o local pretendido para sua instalação, estabelecer mecanismos para o envolvimento das comunidades afetadas pelos impactos (desde as etapas iniciais de concepção do projeto, mas, principalmente, nas demais fases do processo além da análise técnica) e, sobretudo, procurar superar a interferência de fatores externos às questões ambientais na tomada de decisão.

\section{AGRADECIMENTOS}

Os autores agradecem à Fundação de Amparo à Pesquisa de São Paulo - FAPESP pelo auxílio concedido para a realização da pesquisa.

\section{REFERÊNCIAS}

ALMEIDA, M. R.R.; MALFARÁ, D. T.; MENDES, N. C.; MORAES, M. C. P.; SOUZA, M. P.; MONTAÑO, M. Aplicação de métodos para revisão da qualidade de estudos de impacto ambiental. Revista de Gestão Ambiental e Sustentabilidade, v.1, p.3-31, 2012. DOI: http://dx.doi.org/10.5585/geas.v1i2.20
ANDRÉ, P.; ENSERINK, B.; CONNOR, D.; CROAL, P. Public Participation: International Best Practice Principles. Special Publication Series n. 4. International Association for Impact Assessment. Fargo, USA, 2006.

BADR, E. A. Evaluation of the environmental impact assessment system in Egypt. Impact Assessment and Project Appraisal, v.27, n.3, p.193-203, 2009. DOI: http://dx.doi.org/10.3152/146155109X465959

BRASIL. Lei $\mathrm{n}^{\circ}$ 6.938, de 31 de agosto de 1981. Dispõe sobre a Política Nacional do Meio Ambiente, seus fins e mecanismos de formulação e aplicação, e dá outras providências. Diário Oficial da União, Brasília, 2 set. 1981.

CONAMA - Conselho Nacional do Meio Ambiente (Brasil). Resolução n ${ }^{\circ}$ 009, de 03 de dezembro de 1987. Diário Oficial da União, Brasília, 05 dez. 1987.

CONAMA - Conselho Nacional do Meio Ambiente (Brasil). Resolução n ${ }^{\circ}$ 237, de 19 de dezembro de 1997. Diário Oficial da União, Brasília, 19 dez. 1997.

COPAM - Conselho Estadual de Política Ambiental (Minas Gerais). Deliberação Normativa $n^{\circ} 12$ de 13 dezembro de 1994. Minas Gerais, Belo Horizonte, 13 dez. 1994.

COPAM - Conselho Estadual de Política Ambiental (Minas Gerais). Deliberação Normativa n ${ }^{\circ} 074$ de 09 de setembro de 2004. Minas Gerais, Belo Horizonte, 02 out. 2004.

DEVLIN, J. F.; YAP, N. T. Contentious politics in environmental assessment: blocked projects and winning coalitions. Impact Assessment and Project Appraisal, v.26, n.1, p.17-27, 2008. DOI: http://dx.doi. org/10.3152/146155108X279939

ELLIOTT, M.; THOMAS, I. Environmental impact assessment in Australia: theory and practice. 3 ed. Australia: Federation Press, 2009.

EPA - Environmental Protection Authority. Environmental Impact Assessment Procedural Guideline Series 1, 2003. 
FATORELLI, L.; MERTENS, F. Integração de políticas e governança ambiental: o caso do licenciamento rural no Brasil. Ambiente \& Sociedade, v.13, n.2, p.401-415, 2010.

GLASSON, J.; THERIVEL, R.; CHADWICK, A. Introduction to Environmental Impact Assessment. $4^{\mathrm{a}}$ ed. London: Routledge, 2005.

HARTLEY, N.; WOOD, C. Public participation in environmental impact assessment: implementing the Aarhus Convention. Environmental Impact Assessment Review, v.25, p.319-340, 2005. DOI: http://dx.doi. org/10.1016/j.eiar.2004.12.002

HOKKANEN, P.; JANTUNEN, J. A multi-view evaluation of the Finnish EIA system: an 18-year success story? Journal of Environmental Assessment Policy and Management, v.14, n. 4,p.1-22, 2012. DOI: http://dx.doi. org/10.1142/S146433321250024X

IAIA - International Association for Impact Assessment. Principles of environmental impact assessment best practice. Fargo: IAIA, Special Publication v.1, 1999.

KENNEDY, A. J.; ROSS, W. A. An approach to integrate impact scoping with environmental impact assessment. Environmental Management, v.16, n.4, p.475-484, 1992. DOI: http://dx.doi.org/10.1007/BF02394123

KOLHOFF,A.J.; RUNHAAR, H.A.C.; DRIESSEN,P.P. J. The contribution of capacities and context to EIA system performance and effectiveness in developing countries: towards a better understanding. Impact Assessment and Project Appraisal, v.27, n.4, p.271-282, 2009. DOI: http://dx.doi.org/10.3152/146155109X479459

MIDDLE, G.; MIDDLE, I. The inefficiency of environmental impact assessment: reality or myth? Impact Assessment and Project Appraisal, v.28, n.2, p.159-168, 2010. DOI: http://dx.doi. org/10.3152/146155110X498825

MINAS GERAIS. Lei n 2.606, de 05 de janeiro de 1962. Cria o Instituto Estadual de Florestas. Minas Gerais, Belo Horizonte, 8 jan. 1962.
MINAS GERAIS. Decreto ${ }^{\circ} 18.466$, de 29 de abril de 1977. Institui a Comissão de Política Ambiental COPAM e dá outras providências. Minas Gerais, Belo Horizonte, 30 abr. 1977.

MINAS GERAIS. Decreto ${ }^{\circ} 44.667$, de 3 de dezembro de 2007. Dispõe sobre a reorganização do Conselho Estadual de Política Ambiental - COPAM, de que trata a Lei Delegada no 178, de 29 de janeiro de 2007. Minas Gerais, Belo Horizonte, 3 dez. 2007.

MINAS GERAIS. Decreto ${ }^{\circ} 44.814$, de 16 de maio de 2008. Contém o Regulamento do Instituto Mineiro de Gestão das Águas. Minas Gerais, Belo Horizonte, 16 mai. 2008a.

MINAS GERAIS. Decreto $n^{\circ} 44.819$, de 28 de maio de 2008. Contém o Estatuto da Fundação Estadual do Meio Ambiente - FEAM. Minas Gerais, Belo Horizonte, 28 mai. 2008b.

MINAS GERAIS. Decreto $n^{\circ} 45.824$, de 20 de dezembro de 2011. Dispõe sobre a organização da Secretaria de Estado de Meio Ambiente e Desenvolvimento Sustentável. Minas Gerais, Belo Horizonte, 21 dez. 2011.

MONTAÑO, M.; SOUZA, M. P. A viabilidade ambiental no licenciamento de empreendimentos perigosos no Estado de São Paulo. Engenharia Sanitária e Ambiental, v.13, n.4, p.435-442, 2008. DOI: http:// dx.doi.org/10.1590/S1413-41522008000400012

MOREIRA, I. V. D. Avaliação de impacto ambiental - instrumento de gestão. Cadernos FUNDAP, São Paulo, Ano 9, n. 16, p.54-63, 1989.

MORGAN, R. K. Environmental impact assessment: the state of the art. Impact Assessment and Project Appraisal, v.30, n.1, p.5-14, 2012. DOI: 10.1080/14615517.2012.661557

MORRISON-SAUNDERS, A.; EARLY, G. What is necessary to ensure natural justice in environmental impact assessment decision-making? Impact Assessment and Project Appraisal, v.26, n.1, p.29-42, 2008. DOI: 
http://dx.doi.org/10.3152/146155108X3033210 MPF - Ministério Público Federal. Deficiências em Estudos de Impacto Ambiental: sintese de uma experiência. Brasília: $4^{\text {a }}$ Câmara de Coordenação e Revisão, Escola Superior do Ministério Público da União, 2004.

NOBLE, B.; STOREY, K. Towards increasing the utility of 'follow-up' in Canadian EA. Environmental Impact Assessment Review, v.5. n.2, p.163-180, 2005. DOI: http://dx.doi.org/10.1016/j.eiar.2004.06.009

PALIWAL, R. EIA practice in India and its evaluation using SWOT analysis. Environmental Impact Assessment Review, v.26, p.492-510, 2006. DOI: http://dx.doi.org/10.1016/j.eiar.2006.01.004

PETTS, J. Public participation and environmental impact assessment. Handbook of Environmental Impact Assessment, Vol. 1. Environmental Impact Assessment: Process, Methods and Potential. Oxford: J Petts, p.145-177, 1999. DOI: http://dx.doi. org/10.1016/j.eiar.2013.06.003

RAJARAM, T.; DAS, A. Screening for EIA in India: Enhancing effectiveness through ecological carrying capacity approach. Journal of Environmental Management, v.92, p.140-148, 2011. DOI: http:// dx.doi.org/10.1016/j.jenvman.2010.08.024.

RODRIGUES, G. S. S. C. A análise interdisciplinar de processos de licenciamento ambiental no estado de Minas Gerais: conflitos entre velhos e novos paradigmas. Sociedade \& Natureza, v.22, n.2, p.267282, 2010. DOI: http://dx.doi.org/10.1590/S198245132010000200004

ROSS, W. A.; MORRISON-SAUNDERS, A.; MARSHALL, R. Common sense in environmental impact assessment: it is not as common as it should be. Impact Assessment and Project Appraisal, v.24, n.1, p.3-22, 2006.

SADLER, B. (Org.) Environmental assessment in a changeling world, evaluating practice to improve performance. Ottawa: Canadian Environmental Assessment, 1996. 248p.
SÁNCHEZ, L. E. Avaliação de impacto ambiental: conceitos e métodos. São Paulo: Oficina de Textos, 2008. 495p.

SEMAD - Secretaria de Estado de Meio Ambiente e Desenvolvimento Sustentável. Minuta de Deliberação Normativa, 2011. Disponível em: <http://xa.yimg. com/kq/groups/22094367/1687665165/name/ DN_74_quinze_DE_Maio_2011.pdf $>$. Acesso em: 07 out. 2013.

SONERYD, L. Environmental Conflicts and Deliberative Solutions? A case study of public participation in EIA in Sweden. Örebro: Örebro University Press, 2004.

TAMBELlini, A. T. Sobre o Licenciamento Ambiental no Brasil, país - potência emergente. Ciência \& Saúde Coletiva, v.17, n.6, p.13991406, 2012. DOI: http://dx.doi.org/10.1590/S141381232012000600003

THEOPHILOU, V.; BOND, A.; CASHMORE, M. Application of SEA Directive to EU structural funds: perspectives on effectiveness. Environmental Impact Assessment Review, v.30, p.136-144, 2010. DOI: http://dx.doi. org/10.1016/j.eiar.2009.08.001

VASCONCELOS, C; HAMILTON, A.; BARRETT, P. Public participation in EIA: A study from a Portuguese perspective. Journal of Environmental Assessment Policy and Management, v.2, n.4, p.561-582, 2000. DOI: http://dx.doi.org/10.1142/S146433320000045X

VIANA, M. B. Licenciamento ambiental de minerações em Minas Gerais: novas abordagens de gestão. 2007. 305f. Dissertação (Mestrado em Desenvolvimento Sustentável) - Centro de Desenvolvimento Sustentável, Universidade de Brasília, Brasília. 2007.

VIANA, M. B.; BURSZTYN, M. A. A. Regularização ambiental de minerações em Minas Gerais. Revista Escolade Minas, v.63,n.2,p.363-369, 2010.DOI: http:// 
dx.doi.org/10.1590/S0370-44672010000200022

WOOD, G.; BECKER, J. Discretionary judgement in

local planning authority decision making: screening development proposals for environmental impact assessment. Journal of Environmental Planning and Management, v.48, n.3, p.349-371, 2005. DOI: http://dx.doi.org/10.1080/09640560500067467 